\title{
Information About So-Called Idiopathic Scoliosis. New Classification. Examples of Mistreatment and Information About Rules of New Therapy and Prophylaxis
}

\author{
Karski Tomasz ${ }^{* 1}$ and Karski Jacek ${ }^{2}$ \\ ${ }^{1}$ Vincent Pol University in Lublin, Poland \\ ${ }^{2}$ Medical University in Lublin, Poland \\ *Corresponding author: Karski Tomasz, Vincent Pol University in Lublin, Poland
}

\section{ARTICLE INFO}

Received: 㓞 February 06, 2019

Published: 幽 February 22, 2019

Citation: Karski T, Karski J. Information About So-Called Idiopathic Scoliosis. New Classification. Examples of Mistreatment and Information About Rules of New Therapy and Prophylaxis. Biomed J Sci \& Tech Res 15(1)2019. BJSTR. MS.ID.002637.

\begin{abstract}
The biomechanical etiology of the so-called idiopathic scoliosis [old description: adolescent idiopathic scoliosis (AIS)] was a secret deformity over two thousand years. We found that the etiology is biomechanical, is simple and clear for everybody who will check the causes and symptoms, described in the article. In development of scoliosis there are asymmetry of hip movements, in first stages of deformity stiffness of spine only in form of "disappearing of processi spinosi" in thoracic part of spine. Next are coming curves. All children with scoliosis has the habit of "standing"- only on the right leg.
\end{abstract}

Keywords: Scoliosis; New classification; Therapy; Prophylaxis

\section{Introduction}

\section{Spine Scoliosis [1-18]}

The etiology of idiopathic scoliosis was a secret over two thousand years. The biomechanical etiology of scoliosis has been found and described in years 1995 - 2007 (T. Karski, Lublin). The first clinical symptoms of scoliosis are in the region of pelvis and hips, next in spine.

\section{History. Observations from the Years 1984 - 2019}

a) In years 1984 - 1995 - in examination of many patients in Lublin we found the asymmetry of hips movement. The adduction in straight position of a right hip joint in all patients with scoliosis (AIS) was limited. The asymmetry of movement are connected with Syndrome of Contractures and Deformities according of Prof. Hans Mau, Germany (Figure 1).

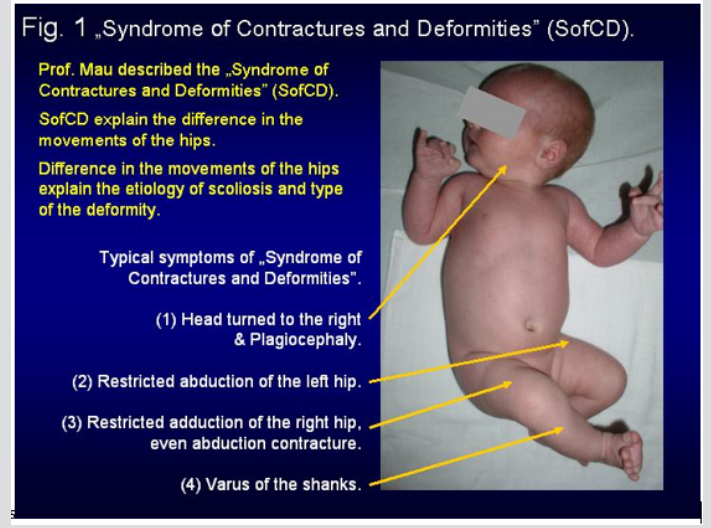

Figure 1: Syndrome of Contractures and Deformities (SofCD). 
b) In 1995 was given the first lecture about biomechanical etiology of AIS in Orthopedic Congress in Szeged in Hungary

c) In 1996 first publication about biomechanical etiology of scoliosis (AIS) in "Orthopädische Praxis" in Germany

d) In 2001 and 2004 describing of three group and four types of so- called idiopathic scoliosis in new classification.

e) In 2006 - definitively describing of three types of hips movement and four types of spine deformity in scoliosis.

f) In 2007 - answer why the full blind children do not have scoliosis. Explanation: other manner of gait - no lifting of legs, no compensatory movement of pelvis and spine. Carefully standing on both legs (confirmation by ophthalmologists) and explanation that Minimal Brain Dysfunction (MBD) through a/ "extension position of trunk", b/ anterior tilt of pelvis and c/ laxity of joint has / make indirect influences of development of scoliosis.

\section{Material}

In the years $1985-2018,2500$ patients mostly in age 5 - 18 were observed and treated. There was also a small group of older patients (60 - 80y), coming with the problem of pain. The older people had no spoken about deformity but about pain. All these older persons had the habit to stand 'et ease' on the right leg.

\section{New Classification (Figures 2-4)}

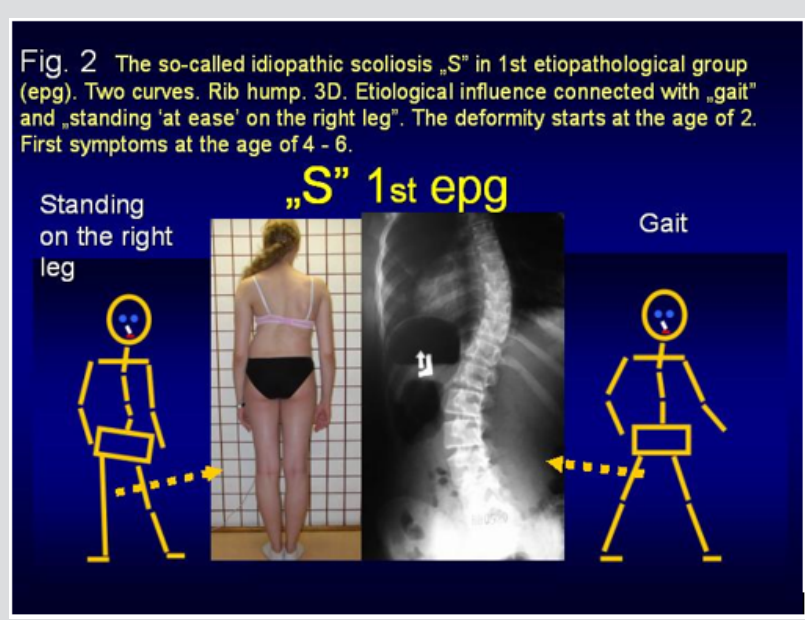

Figure 2: The so-called idiopathic scoliosis ", $S$ " in 1st etiopathological group (epg). Two curves. Rib hump. 3D. Etiological influence connected with "gait" and "standing 'at ease' on the right leg". The deformity starts at the age of 2. First symptoms at the age of $4-6$.

a) Scoliosis "S" $1^{\text {st }}$ etiopathological group (epg) - double curve. The spine is stiff. (3D). Rib hump on the right side of the thorax. Connection with gait and standing „at ease' on the right leg. First symptoms - disappearing of processi spinosi in thoracic part of spine (Th6 - Th12) even in age of 5 - 7. In Adams test we observe stiffness, next curves. b) Scoliosis "C" $2^{\text {nd }} / \mathrm{A}$ epg - one curve - lumbar left convex. Spine flexible (1D or 2D). Connection with standing ,at ease' on the right leg only. In first 2 - 5 years of life of children such standing make the "deformity" only functional and is reversible, but in age of $8-12$ the deformity is fix.

c) Scoliosis "S" $2^{\text {nd }} /$ B epg - two curves, (2D or 3D). Connection with standing 'at ease' on right leg with all properties described by scoliosis "C" $2^{\text {nd }} / \mathrm{A}$ epg, moment earlier and additionally with laxity of joints and /or harmful previous therapy. The spine is flexible.

d) Scoliosis "I" $3^{\text {rd }}$ epg. Deformity has the form of a stiff spine, (2D or 3D). No curves or small ones. The cause is gait only. Such "spine deformity" was till 2004 never classified as "scoliosis". But in our material such deformity we see on 5-8 \% of patients.

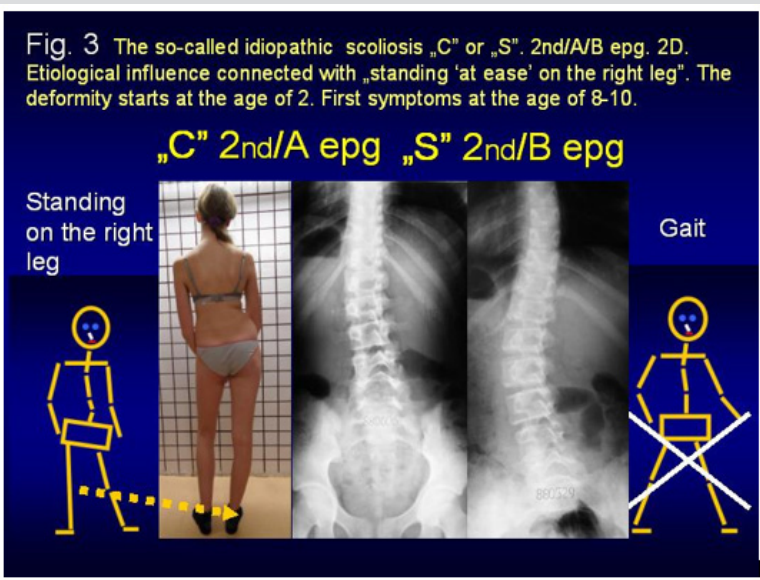

Figure 3: The so-called idiopathic scoliosis "C" or "S". 2nd/A/B epg. 2D. Etiological influence connected with standing 'at ease' on the right leg". The deformity starts at the age of 2 . First symptoms at the age of 8-10.

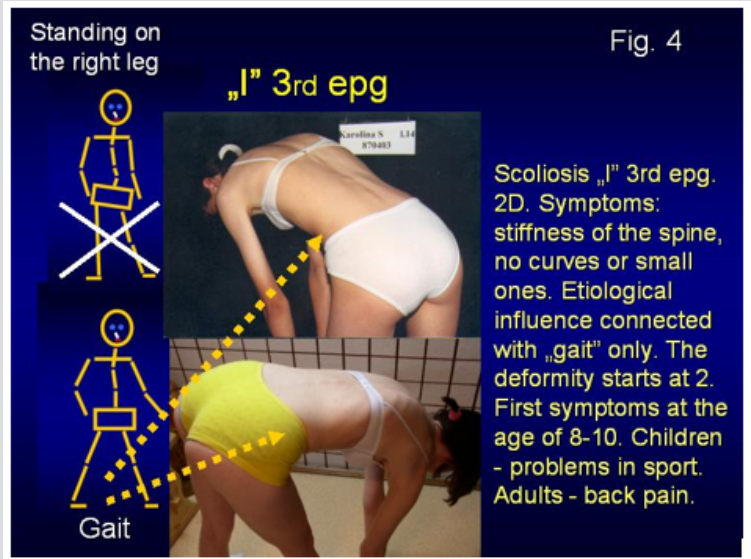

Figure 4: Scoliosis „I" 3rd epg. 2D. Symptoms: stiffness of the spine, no curves or small ones. Etiological influence connected with "gait" only. The deformity starts at 2 . First symptoms at the age of 8-10. Children - problems in sport. Adults - back pain. 


\section{Old, Harmful Therapy. Examples (Figure 5a-5d \& Figure 6a-6c)}

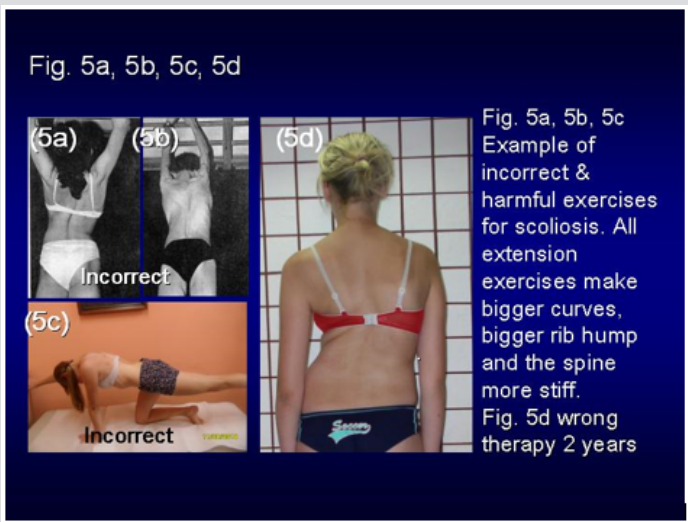

Figure 5: Example of incorrect \& harmful exercises for scoliosis. All extension exercises make bigger curves, bigger rib hump and the spine more stiff. Figure. $5 \mathrm{~d}$ wrong therapy 2 years.

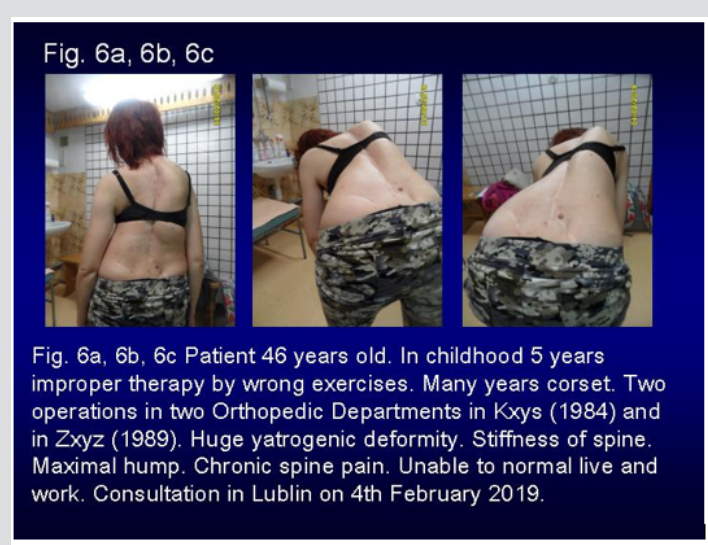

Figure 6: Patient 46 years old. In childhood 5 years improper therapy by wrong exercises. Many years corset. Two operations in two Orthopedic Departments in Kxyz (1984) and in Zxyz (1989). Huge yatrogenic deformity. Stiffness of spine. Maximal hump. Chronic spine pain. Unable to normal live and work. Consultation in Lublin on $4^{\text {th }}$ February 2019.

We are giving the information which exercises were not proper in therapy of scoliosis

a) All extension exercises,

b) All so-called "antigravitation exercise,

c) All exercises if the child was in prone position (on stomach),

d) All exercises to make "strong a muscle of trunk",

e) Using of corset instead of proper therapy,

f) Surgery.
Proper Exercises - Important in Therapy and in Prophylaxis (Figures 7 \& 8)

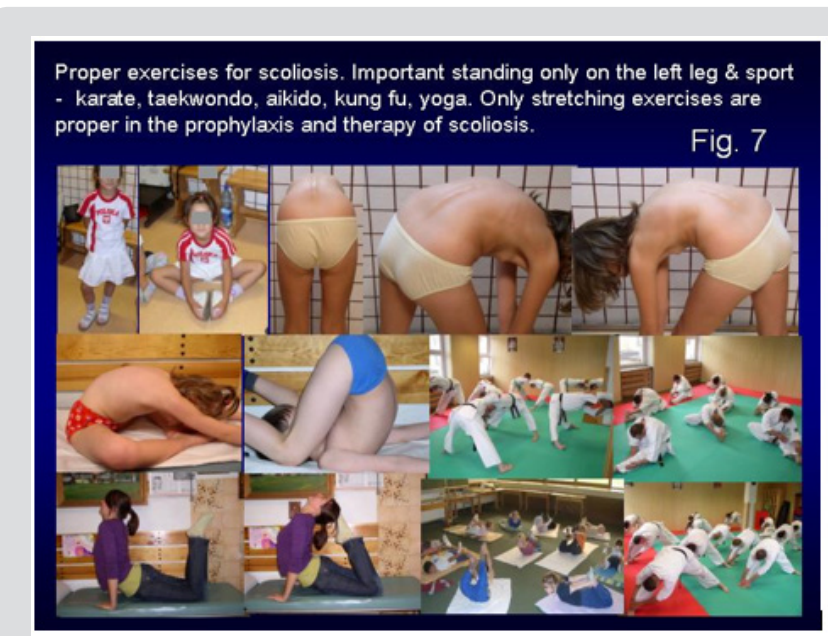

Figure 7: Proper exercises for scoliosis. Important standing only on the left leg \& sport - karate, taekwondo, aikido, kung fu, yoga. Only stretching exercises are proper in the prophylaxis and therapy of scoliosis.

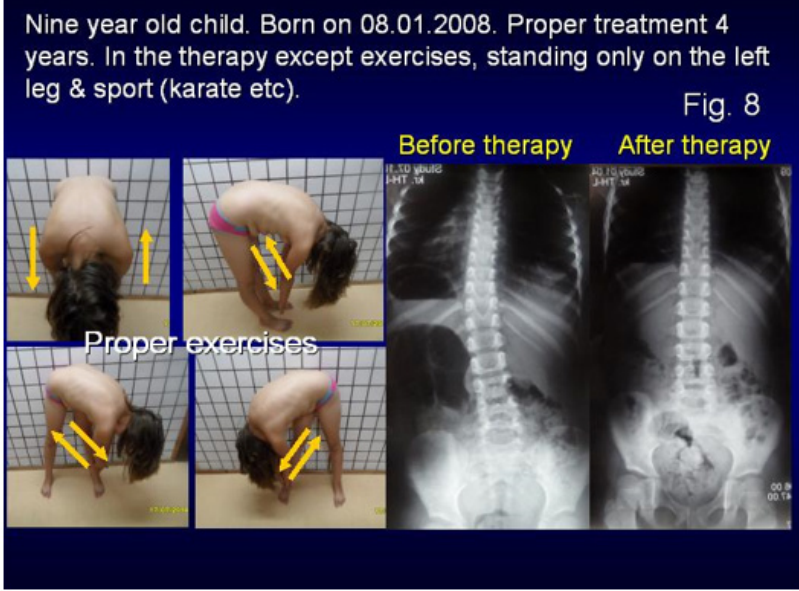

Figure 8: Nine year old child. Born on 08.01.2008. Proper treatment 4 years. In the therapy except exercises, standing only on the left leg \& sport (karate etc).

a) Standing 'at ease' on left leg - no more on the right leg,

b) Sitting in a relaxed position,

c) Sleeping in embryo position,

d) Active participation in sport, in school's gymnastic.

e) Stretching exercises to elongate the soft tissue on concave side of curve, to receive proper position of pelvis and symmetry of movements of both hips. Important are flexion exercise for spine - against stiffness. The prophylactic exercises should be introduced in age of 5 - 6 .

f) Especially important flexion exercises for the spine in all directions (forward flexion, left side flexions, right side 
flexions) - but on the first-place flexions to "convex" side of curve to elongate the "contracted" (shortened) soft tissues on concave side of curve. I would like to recalled, such exercises for the first time have been recommended in Poland by Prof. Stefan Malawski (1975). His therapy was profitable, however the etiology has not been found at that time.

g) Very important are all kinds of sport, but especially proper are such arts sport - like karate, taekwondo, aikido, kung fu, yoga.

h) In cases endangered of "S" scoliosis in 1st group of deformity - it is extremely important to receive the full movement of the right hip as the new, important aim of physiotherapy, in first years of life of child.

\section{Discussion and Comments to the New Knowledge About Scoliosis}

We hope that every scientist in USA and in other country will check the biomechanical causes of spine deformity and the new therapy will be introduced as only one proper method of treatment. We hope that causal prophylaxis will be introduced for every patient in USA and next in all other countries.

\section{Conclusions}

a) Development of the so-called idiopathic scoliosis is connected with biomechanical influences going from the hips.

b) Type of spine deformity is connected with pathological "model of hips movements" (T Karski 2006) and function "standing 'at ease' on the right leg" and "walking" influencing the growth of spine.

c) The restricted range of movements in the right hip as the main factor in oncoming scoliosis is connected with the "Syndrome of Contractures and Deformities" according to Prof. Hans Mau.

d) There are three groups and four types of scoliosis.

e) The proper therapy of scoliosis - are only stretching exercises to receive full movement of right hip, proper position of pelvis and full movement of spine.

\section{References}

1. Burwell G, Dangerfield PH, Lowe T, Margulies J Spine (2000) Etiology of Adolescent Idiopathic Scoliosis: Current Trends and Relevance to New Treatment Approaches. In: Burwell G, Dangerfield PH, Lowe T, Margulies J Spine (Eds.), Hanley \& Belfus Inc, Philadelphia str, USA, pp. 324
2. Green NE, Griffin PP (1982) Hip dysplasia associated with abduction contracture of the contralateral hip. JBJS 64(9): 1273-1281.

3. Hensinger RN (1979) Congenital dislocation of the hip. Clinical Symp 31: 270 .

4. Howorth B (1977) The etiology of the congenital dislocation of the hip. Clin Orthop 29: 164-179.

5. Karski T (2002) Etiology of the so-called "idiopathic scoliosis". Biomechanical explanation of spine deformity. Two 272 groups of development of scoliosis. New rehabilitation treatment. Possibility of prophylactics, Studies in 273 Technology and Informatics, Research into Spinal Deformities 91: 37-46.

6. Karski T, Kalakucki J, Karski J (2006) Syndrome of contractures (according to Mau) with the abduction contracture of the right hip as causative factor for development of the so-called idiopathic scoliosis.

7. Stud Health Technol Inform 123: 34-39.

8. Karski T (2010) Explanation of biomechanical etiology of the so-called idiopathic scoliosis (1995 - 2007). New 276 clinical and radiological classification" in Pohybove Ustroji [Locomotor System] 17(1-2): 26-42.

9. Karski T (2011) Biomechanical Etiology of The So-Called Idiopathic Scoliosis (1995 - 2007) - Connection with 279 "Syndrome of Contractures" - Fundamental Information for Paediatricians in Program of Early Prophylactics 8: 78 .

10. Karski Tomasz (2010) Biomechanical Etiology of the So-called Idiopathic Scoliosis (1995-2007). New Classification: 285 Three Groups, Four Sub-types. Connection with „Syndrome of Contractures”, Pan Arab J. Orth. Trauma 14(2): 69-79.

11. Karski Tomasz (2013) Biomechanical Etiology of the So-called Idiopathic Scoliosis (1995 - 2007). Three Groups and 288 Four Types in the New Classification, Journal of Novel Physiotherapies S2.

12. Karski Jacek, Tomasz Karski (2013) So-Called Idiopathic Scoliosis. Diagnosis. Tests Examples of Children Incorrect 291 Treated. New Therapy by Stretching Exercises and Results, Journal of Novel Physiotherapies 3-2: 9 .

13. Karski Tomasz, Karski Jacek (2015) Syndrome of Contractures and Deformities" according to Prof. Hans Mau as Primary Cause of Hip, Neck, Shank and Spine Deformities in Babies, Youth and Adults American Research Journal of Medicine and Surgery 1(2): 26-35.

14. Karski Tomasz (2019) Opinions and Controversies in Problem of The So-Called Idiopathic Scoliosis. Information About Etiology, New Classification and New Therapy. Biomedical Journal of Scientific \& Technical Research (BJSTR, 2019).

15. Mau H (1979) Zur Ätiopathogenese von Skoliose, Hüftdysplasie und Schiefhals im Säuglinsalter. Zeitschrift f. 294 Orthop 5: 295, 601-605.

16. Mau H (1982) Die Atiopatogenese der Skoliose, Bücherei des Orthopäden, Band 33, Enke Verlag Stuttgart, 1- 296: 110

17. Normelly $H$ (1985) Asymmetric rib growth as an aetiological factor in idiopathic scoliosis in adolescent girls, 298 Stockholm 1-103: 299.

18. Sevastik J, Diab K (1997) Studies in Technology and Informatics, Research into Spinal Deformities 37: 1-509.

19. www.ortopedia.karski.lublin.pl. 
ISSN: 2574-1241

DOI: 10.26717/BJSTR.2019.15.002637

Karski Tomasz. Biomed J Sci \& Tech Res

CC (i) This work is licensed under Creative

Submission Link: https://biomedres.us/submit-manuscript.php

$\begin{array}{ll}\text { BIOMEDICAL } & \text { Assets of Publishing with us } \\ \text { RESEARCHES } & \text { - Global archiving of articles } \\ & \text { - Immediate, unrestricted online access } \\ & \text { - Rigorous Peer Review Process } \\ & \end{array}$

